\title{
Configurações
}

Revista de sociologia

$10 \mid 2012$

Políticas Públicas

\section{Crise, desenvolvimentismo e tendências das políticas sociais no Brasil e na América Latina}

Crisis, development and tendencies of the social policies in Brazil and Latin America

Crise, développement et les tendances des politiques sociales au Brésil et en Amérique Latine

\section{Ana Elizabete Mota}

\section{(2) OpenEdition}

\section{Journals}

Edição electrónica

URL: http://journals.openedition.org/configuracoes/1324

DOI: $10.4000 /$ configuracoes. 1324

ISSN: 2182-7419

\section{Editora}

Centro de Investigação em Ciências Sociais

\section{Edição impressa}

Data de publição: 1 Dezembro 2012

Paginação: 29-41

ISBN: 1646-5075

ISSN: 1646-5075

\section{Refêrencia eletrónica}

Ana Elizabete Mota, "Crise, desenvolvimentismo e tendências das políticas sociais no Brasil e na América Latina », Configurações [Online], 10 | 2012, posto online no dia 17 fevereiro 2014, consultado o 19 abril 2019. URL : http://journals.openedition.org/configuracoes/1324 ; DOI : 10.4000/ configuracoes. 1324

Este documento foi criado de forma automática no dia 19 Abril 2019.

(c) CICS 


\title{
Crise, desenvolvimentismo e tendências das políticas sociais no Brasil e na América Latina
}

\author{
Crisis, development and tendencies of the social policies in Brazil and Latin
}

America

Crise, développement et les tendances des politiques sociales au Brésil et en

Amérique Latine

Ana Elizabete Mota

\section{Introdução}

1 A oportunidade de realizar um estágio pós-doutoral em Portugal, num ambiente marcado pelas medidas de enfrentamento da crise e que afetam diretamente os trabalhadores dos setores público e privado, além dos reformados, com altas taxas de desemprego, cortes salariais e nos orçamentos da educação e dos demais serviços públicos, com a supressão de direitos que os portugueses consideravam consolidados, me instigou a escrever este artigo. De facto, não é incomum ouvir em todos os lugares a frase: "o Brasil é que está bem, a Europa está mal...”. Da periferia europeia aos países nórdicos, esta é uma afirmação presente no senso comum. De tal modo que a equação austeridade versus crescimento econômico foi transformada em paradigma de análise do enfrentamento da crise, a se apresentar como conceito-chave na mídia e incorporado ao saber popular e letrado.

Enquanto no além-mar se desenvolve uma verdadeira cultura da crise (Mota, 1995) levada a efeito pelas classes dominantes, na tentativa de se obter consensos sobre as medidas de austeridade impostas pela troika, no Brasil e nos demais países da América Latina também se identifica um movimento formador de cultura pelas classes dominantes, diga-se, nomeadamente, de pós-crise, a espraiar, desta feita, práticas e ideologias que tornam 
consensual a ideia de que a superação da crise capitalista se faz pelo crescimento da economia e combate à pobreza (Mota, 2013).

Evidente que esses movimentos na Europa e na América Latina comportam propósitos imediatos distintos, porém não revelam nenhum antagonismo, por possuírem uma unidade subjacente: a precarização do trabalho, a reiteração das desigualdades sociais e a manutenção da mundialização financeira (Chesnais, 1996), sob os auspícios da reforma do Estado em prol dos interesses do grande capital. Assim, sou instigada a pensar que, em face das medidas de enfrentamento da crise capitalista, as vias da austeridade e do crescimento econômico materializam "modelos" desenvolvidos em conjunturas particulares, mas determinados pela hegemonia das finanças e pelas estratégias de restauração da dinâmica capitalista.

4 Enquanto a Europa inaugura a austeridade neoliberal, como dão mostras a situação de Portugal, Espanha e Grécia, o Brasil e os demais países latinoamericanos, herdeiros dos ajustes ditados pelo FMI, abraçam o neodesenvolvimentismo e a ideologia do socialliberalismo como meios de superação da crise do capital. Contudo, ambos os processos são expressões do realinhamento das relações entre Estado, mercado e classes sociais.

5 Feito este curto prólogo, esclareço que o meu texto se debruçará sobre a realidade brasileira e latino-americana, sem que tenha o propósito de fazer uma abordagem comparada com o caso europeu. Meu objetivo é refletir sobre a estratégia neodesenvolvimentista adotada pelos governos de centro-esquerda no Brasil e nos demais países do subcontinente latino-americano, com destaque para o caso brasileiro, cuja característica é a combinação de financeirização, crescimento econômico e políticas sociais compensatórias. Discorrerei sobre os fundamentos da crise capitalista deste século e abordarei o principal princípio da estratégia neodesenvolvimentista, que é o binômio crescimento econômico versus políticas de combate à pobreza, no intuito de analisar seus pressupostos e destacar as funcionalidades e contradições desse processo. Por fim, concluo que a estratégia social-liberalista tem incidência na redução da pobreza, todavia não produz impactos na redução da histórica desigualdade social que prevalece no Brasil e demais países latinoamericanos.

\section{A dinâmica das crises: aspetos teóricos, históricos e conjunturais}

6 Obviamente, de meados do século XIX até este início do século XXI, o modo de produção capitalista transformou-se notavelmente. Hoje, a diferença central em relação ao passado é o diminuto horizonte economicamente expansivo do capitalismo, no quadro da crise geral do assalariamento, dos mecanismos públicos de proteção social e da organização política dos trabalhadores no cenário da expansão e hipertrofia do capital financeiro e da subtração das responsabilidades sociais do Estado.

7 O surgimento da sociedade urbano-industrial compôs o ambiente no qual os trabalhadores se organizaram e politizaram as suas necessidades e carecimentos, a transformá-los numa questão pública e coletiva que passou a ser socialmente reconhecida pelo Estado, a originar o modernamente denominado de Estado Social ou de Bem-Estar Social (Welfare State), ancorado em direitose garantias sociais, que se expandiu a partir da Segunda Guerra Mundial, a se configurar como uma vitória do movimento operário. 
8 É evidente que o Estado Social se mostrou necessário ao capitalismo do pós-guerra, uma vez que possibilitou o surgimento de ideologias que defendiam a possibilidade de compatibilizar capitalismo, bem-estar e democracia, lastro político da social-democracia que perdurou pelas três décadas gloriosas de crescimento ${ }^{1}$. Todavia, enquanto os países centrais asseguravam a reprodução do crescimento econômico com desenvolvimento social, na periferia mundial assistia-se à defesa da modernização e do desenvolvimentismo como meio de integração desses países à ordem econômica mundial.

9 A plena incorporação das economias periféricas ao processo de reprodução ampliada do capital veio a ocorrer nos anos 70 do século XX, quando os países então chamados subdesenvolvidos transformaram-se em campo de absorção de investimentos produtivos. A seus Estados nacionais coube o papel de indutores do desenvolvimento econômico, a propiciar uma base produtiva integrada às necessidades dos oligopólios internacionais, graças ao apelo ao crédito externo para o financiamento daquela base e sua expansão. Esta situação altera-se na década seguinte, quando se inicia a crise da dívida externa, e obriga tais países, sistematicamente, a exportar capitais para o pagamento dos juros e dos empréstimos recebidos. Não por acaso, em tal período o mundo capitalista oferece os sintomas de uma crise de acumulação, o que obrigou os países desenvolvidos a redefinirem suas estratégias de acumulação.

Instala-se, no âmbito do sistema capitalista e na sua economia-mundo, muito mais do que uma crise econômica: estão postas as condições de uma crise orgânica ${ }^{2}$, marcada pela perda dos referenciais erigidos sob o paradigma do fordismo, do keynesianismo, do Welfare State e das grandes estruturas sindicais e partidárias, a que se soma o esgotamento do socialismo real, o que vem a afetar a combatividade do movimento operário.

11 Em face desta dinâmica, a restauração capitalista, tal como analisada por Braga (1996), configurou-se como uma resposta à crise, a determinar tanto a reestruturação dos mecanismos de acumulação como a redefinição de mecanismos ideopolíticos necessários à formação de novos e mais eficientes consensos hegemônicos. Orquestrada pela ofensiva neoliberal, a ação sociorreguladora do Estado se retrai e pulveriza os meios de atendimento às necessidades sociais dos trabalhadores entre organizações privadas mercantis e não mercantis, bem como limita sua responsabilidade social à segurança pública, à fiscalidade e ao atendimento, por meio da assistência social e das políticas de inserção, daqueles absolutamente impossibilitados de sobreviver.

Qualificados por muitos como um período em que o trabalho perdeu a sua centralidade ou um período no qual o capitalismo deixou de ter medo, fato é que os anos que se seguem à década de 80 são palco da restauração capitalista, assentada num duplo movimento: a) a redefinição das bases da economia-mundo através da reestruturação produtiva e das mudanças no mundo do trabalho (Mota, 1995); e a ofensiva ideopolítica necessária à construção da hegemonia do grande capital, evidenciada na emergência de um novo imperialismo e de uma nova fase do capitalismo, marcada pela acumulação com predomínio rentista (Harvey, 2005).

Do ponto de vista macroeconômico, o que está em processo de consolidação é a acumulação por espoliação, sob o comando dos países ricos (Harvey, 2005). O veículo primário da acumulação por espoliação tem sido a abertura forçada de mercados em todo o mundo, mediante pressões institucionais exercidas por meio do FMI e pela OMC. Este processo torna campo de investimento transnacional desde o patenteamento de pesquisas 
genéticas, até a transformação de serviços sociais em negócios - como está a ocorrer com a saúde, a segurança social e a educação.

14 A mercantilização da esfera da reprodução é também um dos novos traços desta fase, a repercutir em dois níveis: na expropriação e mercantilização de atividades domésticas e privadas não mercantis e na superexploração dos trabalhadores e das famílias. A privatização dos serviços os impele a retirar parte dos seus salários para comprar seguros e planos privados de saúde, complementação das aposentadorias e educação; particularmente, no caso das mulheres dos países periféricos, além das duplas jornadas de trabalho, são obrigadas a incorporar, como parte das suas atividades domésticas, um conjunto de afazeres que deveria ser de responsabilidade pública, a exemplo dos cuidados, dentre outros serviços.

15 A ofensiva político-social e ideológica para assegurar a reprodução desta realidade passa pela reforma do Estado e pela redefinição de estratégias que devem ser formadoras de cultura e sociabilidade, imprescindíveis à gestação de uma reforma intelectual e moral ${ }^{3}$ conduzida pelo grande capital para estabelecer novos pactos e parâmetros para o atendimento das necessidades sociais - sem romper com a lógica da acumulação e do lucro. Essa reforma busca transformar o cidadão sujeito de direitos num consumidor; os trabalhadores em empreendedores e os desempregados em utentes da assistência social.

Em suma, penso não existirem dúvidas de que se está diante da mais profunda crise do sistema capitalista, a qual expõe as contradições da dinâmica da acumulação e se manifesta em diversas frentes: a financeira, a ambiental, a urbana e a do emprego, para mencionar as suas mais destacadas expressões.

Como afirmou Marx (1998), as crises são inerentes ao desenvolvimento do capitalismo, dado que a produção capitalista cria barreiras à sua própria expansão. Ao procurar superá-las, somente o faz por meio de movimentos restauradores que, ciclicamente, repõem novas barreiras ao seu desenvolvimento. Este processo é determinado pela incessante busca de lucros e mediado por iniciativas econômicas e políticas que permitem tanto a existência de períodos em que prevalece a destruição massiva das forças produtivas quanto a emergência de ciclos de prosperidade, historicamente em alternância.

Note-se, por exemplo, que na década de 80/90 a crise foi concebida como esgotamento de um modelo (o fordista-keynesiano), razão da proposta de menos Estado, mais mercado e a supressão das regulamentações do trabalho e de qualquer controle do capital, em prol do projeto neoliberal. Num segundo momento, a partir dos anos 2000, o discurso e as estratégias de enfrentamento da crise se afastam das loas à desregulamentação do mercado e passam a transitar por uma espécie de juízo moral que, ao criticar os maus e desonestos capitalistas - qualificados de especuladores irresponsáveis -, defende o capitalismo sério, real, produtivo, democrático e redistributivo.

Estava dado o "impulso" ideológico que marcaria o início de outra processualidade histórica na região, desta feita, qualificada pelo discurso oficial como um meio de enfrentamento à crise do capital financeiro, a revelar um novo processo de restauração da ordem, agora conduzido por outros protagonistas: os governos de centro-esquerda latino-americanos que abraçaram o social-liberalismo e o novo-desenvolvimentismo (Castelo, 2010), que têm na diretriz crescimento econômico com desenvolvimento social sua orientação basilar. 
20 Poder-se-ia ressaltar a positividade deste projeto ao reconhecer que ele opera algumas inflexões na ortodoxia neoliberal. Afinal, ele supõe a intervenção do Estado como indutor do crescimento econômico, a ampliação e a formalização do emprego, dentre outros aspetos que, pelo menos em tese, negariam a centralidade do mercado. Duas ideias centrais sintetizam seus pressupostos: a) a de que o enfrentamento ao neoliberalismo se faz com crescimento econômico mediado pela intervenção do Estado; b) e a de que o crescimento econômico leva inexoravelmente ao desenvolvimento social.

21 A rigor, como argumentou Karl Polanyi (2000), o Estado nunca esteve ausente da economia capitalista. Todavia, na atualidade, ele redefine sua ação, e o faz numa conjuntura específica: os mesmos personagens que impuseram os ajustes nos anos $1980 \mathrm{e}$ 90 do século XX na América Latina, diante do agravamento da pobreza e da força dos movimentos sociais que destituíram mais de uma dúzia de presidentes neoliberais, iniciam uma revisão das suas propostas pós-consenso de Washington. Denominadas de políticas de segunda geração, elas alteram as diretrizes sobre os ajustes estruturais e instituem o financiamento de programas de alívio à pobreza nos países periféricos. Este novo direcionamento foi protagonizado na gestão do Banco Mundial de James Wolfensohn ${ }^{4}$, também endossada por Joseph Stiglitz, a determinar as tendências do desenvolvimento social em curso na região: a manutenção das reformas de cunho neoliberal com expansão das políticas de assistência social e de rendas mínimas ou de inserção, voltadas para a redução dos níveis extremos de pobreza. Um dos elaboradores dessa proposta, o economista Amartya Sen, era então membro da presidência do próprio Banco Mundial, e sua proposta de "desenvolvimento como liberdade" (Sen, 2000) foi plenamente incorporada pela instituição. Na sua perspetiva, são necessários esforços na remoção de obstáculos do desenvolvimento da sociedade (pobreza, carência de oportunidades econômicas, negligência dos serviços públicos), considerados entraves ao pleno desenvolvimento à liberdade de acesso do indivíduo ao mercado.

\section{Tendências das Políticas Sociais no Brasil e na América Latina}

22 A partir da década de 1990, o movimento das esquerdas latino-americanas orienta-se no sentido da resistência ao neoliberalismo, culminando com eleições parlamentares que levaram ao poder governos de esquerda e centro-esquerda em países da região, a exemplo de Brasil, Argentina, Uruguai, Bolívia, Equador e Venezuela. Nos anos 2000, esses setores progressistas chegam ao poder com discursos anti-imperialistas e em defesa do desenvolvimento nacional e da autonomia dos estados nacionais, após décadas de injunção dos organismos financeiros internacionais em favor das políticas de ajuste estrutural.

Esta perspetiva é denominada de novo-desenvolvimentismo e tem suas bases de fundamentação, embora sob outras determinações, no chamado nacionaldesenvolvimentismo, que orientou a economia dos países subdesenvolvidos, no período de 1940 até a década de 1970 do século passado, sob a orientação da Comissão Econômica para América Latina e Caribe (CEPAL) 5 .

24 Vale ressaltar que no final dos anos 80 do século XX, com a emergência do neoliberalismo, a CEPAL ajusta o seu discurso da década de 1970 em compasso com as prerrogativas do mercado, da crescente financeirização da economia e da necessária redução do Estado. É 
nessa conjuntura que emerge neodesenvolvimentismo, caracterizado como "uma estratégia de desenvolvimento alternativo aos modelos em vigência na América do Sul, (...) cujo principal objetivo é delinear um projeto nacional de crescimento econômico combinado com uma melhora substancial nos padrões distributivos do país" (Castelo 2010:194).

Os defensores do neodesenvolvimentismo sustentam que o consenso neoliberal e seus preceitos privatizantes não conseguiram resolver questões centrais dos países periféricos. Seus adeptos consideram que algumas políticas e ações são fundamentais para repor na agenda dos países da região os mecanismos de distribuição dos recursos, de modo a enfrentar a questão da desigualdade. Em linhas gerais, defendem o investimento em políticas sociais e educacionais como fatores estratégicos no sentido da inclusão social, da melhoria na distribuição de renda e da redução das desigualdades causadas pela globalização do mercado (Sicsú, Paula e Michel, 2005).

Ademais, em contrapartida à destrutividade e à exploração dos recursos naturais (petróleo, gás etc.), propõe-se, em quase toda a América Latina, a apropriação da renda proveniente da exploração destes recursos para financiar o Estado e seus programas sociais, a legitimar a produção destrutiva da natureza através de discursos que a justificam sob os argumentos da criação de postos de trabalho e do combate à pobreza.

27 Esse raciocínio, entretanto, não se restringe à compensação da exploração do subsolo; a rigor, fundamenta a direção política dos governos de esquerda e centro-esquerda que abraçaram a hipótese do crescimento econômico com expansão de políticas sociais compensatórias em toda a América Latina como um projeto de superação das históricas desigualdades sociais.

28 Todavia, a realidade não aponta possibilidades de êxito nesse processo, apesar de ter havido redução da pobreza. Constata-se na América Latina que mais de $40 \%$ de sua população é pobre e entre $15 \%$ a $20 \%$ são indigentes; as desigualdades sociais aumentaram; porém, o que muda é a criação de outros meios de enfrentamento da pobreza, com políticas de inclusão, por cotas, ou de mínimos sociais.

29 Segundo a Comissão Econômica para a América Latina e o Caribe (Cepal, 2010), no Relatório Programa de Assentamentos Humanos da Organização das Nações Unidas (ONUHabitat), os $20 \%$ latino-americanos mais ricos concentram $56,9 \%$ da riqueza da região. Os $20 \%$ mais pobres, por sua vez, recebem apenas 3,5\% da renda, o que faz dessa região uma das mais desiguais do mundo. Ainda esta mesma fonte informa que, no Brasil, os $10 \%$ mais ricos concentram $50,6 \%$ da renda, enquanto os $10 \%$ mais pobres ficam com apenas $0,8 \%$; na Argentina, os $10 \%$ mais ricos concentram $41,7 \%$ da renda, e os $10 \%$ mais pobres, $1,1 \%$; na Venezuela, os $10 \%$ mais ricos têm $36,8 \%$ da renda, e os $10 \%$ mais pobres, $0,9 \%$; na Colômbia, os $10 \%$ mais ricos têm $49,1 \%$ da renda, e os $10 \%$ mais pobres, $0,9 \%$.

30 Adicionalmente, Katz (2009) informa que a América Latina suporta um abismo de desigualdades sociais, superior ao de qualquer outra zona do planeta. A diferença que separa os $10 \%$ mais ricos dos $10 \%$ mais pobres alcança 157 vezes na Bolívia, 57 vezes no Brasil, 76 vezes no Paraguai, 67 vezes na Colômbia, 46 vezes no Equador e 39 vezes no Chile. O caso brasileiro é mais significativo pela dimensão e pelo poderio econômico do país. Ali, os $10 \%$ mais ricos possuem quase $75 \%$ da riqueza total, enquanto os $90 \%$ mais pobres ficam somente com $25 \%$.

31 O que chama atenção é o fato de que não estejam a se efetivar reformas substantivas que revertam o desmonte neoliberal das políticas. O que o cenário continental mostra é a 
expansão de políticas de exceção, de ingressos, em substituição ao direito ao trabalho, como exposto no quadro $\mathrm{n}^{\circ} 1$.

Quadro 1 - Programas de transferência de rendas na América Latina

Quadro 1 - Programas de transferência de rendas na América Latina

\begin{tabular}{llr}
\hline País & Programa & Ano \\
\hline Nicarágua & Red de Protección Social & 2000 \\
\hline \multirow{2}{*}{ Costa Rica } & Superémonos & 2000 \\
& Avancemos & 2006 \\
\hline \multirow{2}{*}{ Colômbia } & Familia en Acción & 2001 \\
& Red Juntos & 2007 \\
& Subsidios Condicionados a la Asistencia Escolar & 2005 \\
\hline \multirow{2}{*}{ Brasil } & Bolsa Escola & 2001 \\
& Bolsa Família & 2003 \\
\hline \multirow{2}{*}{ Argentina } & Jefes de Hogar & 2002 \\
& Familias por la Inclusión & 2005 \\
\hline Chile & Asignación Universal por Hijo & 2009 \\
\hline Peru & Chile Solidário & 2002 \\
\hline El Salvador & Programa Juntos & 2005 \\
\hline Paraguai & Comunidades Solidarias Rurales & 2005 \\
\hline Uruguai & Tekoporã & 2005 \\
\hline República & Ingreso Ciudadano & 2005 \\
\hline Dominicana & Programa Solidaridad & 2005 \\
\hline Panamá & Red de Oportunidades & 2005 \\
\hline \multirow{2}{*}{ Bolívia } & Bono Escolar “Juancito Pinto" & 2006 \\
\hline
\end{tabular}

FONTE: CEPAL, AgENCIA SUECA DE COOPERACIÓN INTERNACIONAL PARA EL DESARROLLO (ASDI), SANTIAgO dE CHILE, JUNIO de 2011. NOTA: ElABORAÇÃo PERUZZO, AMARAL E MOTA,2012.

Inegavelmente, estas políticas permitem o aumento do consumo das famílias pobres, porém não interferem na origem das desigualdades. Note-se que as políticas sociais mais estruturadoras, como a saúde, as reformas/aposentadorias, a educação, dentre outras que os governos neoliberais transformaram em serviços mercantis, são objeto de uma forte reação da direita continental, historicamente patrimonialista, oligárquica e antirreformista, ante qualquer iniciativa de universalização. Qualquer ação que permita democratizar o acesso a bens e serviços públicos, assim como instituir mecanismos de controle no âmbito da sociedade, é suficiente para desencadear a ofensividade da direita, contra o que eles identificam de populismo radical. Todavia, as políticas focais são apoiadas e vêm sendo objeto de parcerias entre os setores público e privado.

Estas considerações não obscurecem a existência de novas respostas políticas aos vinte anos do neoliberalismo no subcontinente, porém elas não superaram a herança neoliberal com a destruição dos direitos e das políticas que, junto com as ideias pós-modernas e a cooptação dos movimentos sociais, têm afetado as ideologias classistas em favor de outra concertação de classes.

Do meu ponto de vista, está em curso um processo de repolitização regressiva da política, que se faz com os argumentos antineoliberais e anti-imperialistas, mas em defesa do nacional-capitalismo, cuja principal mediação não são reformas sociais com impacto na redistribuição da renda, mas políticas focais de alívio à pobreza. A intervenção social dos governos progressistas tem sido marcada pela criação de programas compensatórios de 
enfrentamento da pobreza, como demonstra o quadro $\mathrm{n}^{\circ} 1$, notadamente a partir dos anos 2000.

35 Sob essa perspetiva, aloja-se a despolitização das lutas e do caráter classista das desigualdades sociais, que passam a ser entendidas ora como exclusão, ora como evidência da desfiliação em relação à proteção estatal, ambas confluindo na defesa de estratégias de inclusão e inserção, a permitir que o existente se transforme em ideal, e a sitiar, assim, a construção de projetos societais emancipatórios.

\section{Conclusão}

É incontestável o crescimento econômico e a redução da pobreza no subcontinente latinoamericano, particularmente no Brasil. Todavia, as evidências recentes revelam um ambiente no qual as classes dominantes operam uma "renovação" da sua estratégia de poder (hegemonia) e incorporam, via mecanismos políticos, parte das reivindicações e lutas populares, a dar andamento à formação de uma cultura na qual o crescimento econômico se faz com o combate à pobreza. Ao tempo que criam mecanismos de intervenção sobre as situações emergenciais de pobreza, sem configurar direitos universais nem instituí-las como política pública, senão como programa de governo, dinamizam o mercado interno, precarizam o trabalho, expandem o crédito ao consumidor e promovem espaços de mercantilização dos serviços sociais na esfera da educação, da saúde e da segurança social, além de produzir verdadeiras usinas de trabalho precário de que são exemplares, no caso do Brasil, as obras da Copa do Mundo, do Complexo Industrial e Portuário de Suape, em Pernambuco, e as hidroelétricas situadas no norte do país.

A tendência atual das políticas públicas é a da privatização e mercantilização dos serviços públicos nos setores saúde, previdência (reformas) e educação, e a expansão da assistência social, particularmente dos programas de renda mínima de sobrevivência. Nesta perspetiva, os investimentos em programas assistenciais focalizados e condicionados se fazem em oposição aos gastos com políticas sociais universais e estão longe de indicar um novo modelo de desenvolvimento social para o Brasil e demais países latinoamericanos, mas têm sido úteis na dinamização dos mercados internos, na legitimidade social da classe dominante e na administração dos conflitos sociais.

Inegavelmente, o Estado trabalha em duas posições: mercantilização e assistencialização da política pública, embora divulgue mundialmente que está a desenvolver um Estado social. $\mathrm{Na}$ contraface, os fundos públicos confluem para a valorização do capital, na medida em que a dívida pública tem sido uma fonte da sua valorização (Behring, 2012). Uma parcela cada vez maior dos impostos arrecadados de forma regressiva é destinada ao pagamento de juros a grandes grupos financeiros e fundos de investimento e de pensão. Nesse sentido, as supressões do acesso a bens e serviços sociais públicos se convertem em demandas para negócios privados, cujo acesso é mediado pela compra realizada com parte dos salários dos trabalhadores.

Na dialética da dependência, Marini (2005) afirma que o capitalismo desenvolve duas grandes formas de exploração: o aumento da força produtiva do trabalho e a exploração do trabalhador. No primeiro caso, o aumento da produtividade do trabalho, logo, mais mercadorias produzidas no mesmo tempo de trabalho e com o mesmo gasto de energia. No caso da exploração do trabalhador, estão o aumento da jornada, a maior intensidade 
do trabalho e a redução do fundo de consumo do trabalhador. As expropriações de direitos em paralelo à oferta de serviços privados antes considerados um direito de cidadania podem ser consideradas como formas de superexploração do trabalho (Graneman, 2005; Fontes, 2010). Uma parcela do salário destina-se à compra de serviços sociais - como saúde, previdência complementar e educação, dentre outros.

Trata-se do processo de contrarreforma do Estado (Behring, 2003), expressão que nomeia a particularidade da "reforma social" brasileira, visto que somente em 1988 são constitucionalmente reconhecidos os direitos sociais, especialmente os da seguridade social, não obstante, na década de 90 , iniciarem-se mudanças que desmontam aquelas políticas.

41 Note-se que o Brasil sedia o maior programa de transferência de rendas da América Latina, o qual atende $26,4 \%$ das famílias da população, com um gasto de $0,47 \%$ do PIB, enquanto a dívida pública é de $\mathrm{R} \$ 1,514$ trilhão, o equivalente a $35,7 \%$ do PIB; já os juros da dívida pública consumiram em 2011, 5,72\% do PIB. No orçamento geral da União de 2011 , foram utilizados $45 \%$ dos recursos do orçamento somente para pagamento dos juros da dívida. Por outro lado, foram destinados apenas 4,07\% para a Saúde, 2,99\% para a educação, 2,85\% para a assistência social, conforme estudos da auditoria cidadã da dívida (Boschetti, 2012). E mais, segundo o Relatório de Atividades da Superintendência Nacional de Previdência Complementar (PREVIC, 2011), órgão responsável pela supervisão dos fundos de pensão no país, existem 338 Entidades Fechadas de Previdência Complementar (Fundos de Pensão) com 3 milhões de participantes, movimentando ativos da ordem de R\$ 603 bilhões. Dados da Agência Nacional de Saúde Suplementar (ANS) (2011) revelam que existiam no Brasil, em 2010, 1.619 operadoras de planos de saúde com registro na Agência e um total de 46,6 milhões de beneficiários de planos privados de assistência médica.

Estes dados evidenciam que a pequena redução da pobreza, ainda que importante, não significa redução da desigualdade, nem expressiva melhoria nas condições de vida da população brasileira. Assim, o festejado crescimento econômico e a redução da pobreza escondem a drástica e persistente desigualdade entre ricos e pobres, as imensas distâncias entre o menor e o maior salário vigentes, o reduzido acesso às políticas sociais, a precarização do trabalho e a sangria de recursos para alimentar o pagamento dos juros da dívida pública.

43 No plano intelectual, subjaz a esta tendência uma conceção de questão social que se afasta da relação entre o processo de pauperização relativa dos trabalhadores e o de acumulação capitalista, para ser identificada como pobreza, enquanto fenômeno social. Desse modo, o tratamento da questão social como pobreza se torna compatível com as novas exigências do capitalismo do século XXI, com o intuito de culturalizar a sociedade, ao considerar que reduzir a pobreza é enfrentar a desigualdade, sem reformas universalizantes e com políticas focais.

É nesse sentido que advogo conclusivamente o seguinte: o que está posto no horizonte é uma nova reforma cultural social e moral por parte das classes dominantes, numa invisível aliança entre as necessidades do grande capital e as políticas focalizadas na pobreza, ao tempo que se impõe a superexploração dos trabalhadores médio-assalariados. 


\section{BIBLIOGRAFIA}

BEHRING, Elaine R. (2003), Brasil em Contra-Reforma: desestruturação do Estado e perda de direitos, São Paulo: Cortez.

BEHRING, Elaine R. (2003), “Rotação do Capital e Crise: Fundamentos para compreender o fundo público e a política social”, in Evilasio Salvador et al. (org), Financeirização, Fundo Público e Política Social, São Paulo: Cortez.

BRAGA, Ruy (1996), A Restauração do Capital. Um estudo sobre a crise contemporânea, São Paulo: Xamã.

BOSCHETTI, Ivanete (2011), “Os custos da crise para a política social”, in Ivanete Boschetti et al. (org.), Capitalismo em crise. Política social e direitos, São Paulo: Cortez.

BOSCHETTI, Ivanete (2012), “América Latina, Política Social e Pobreza: novo modelo de desenvolvimento?” in Salvador et al. (org), Financeirização, Fundo Público e Política Social, São Paulo: Cortez.

CASTELO BRANCO, Rodrigo (2010), “O novo-desenvolvimentismo e a decadência ideológica do estruturalismo latino-americano", in Castelo Branco (Org.), Encruzilhadas da América Latina no século XXI, Rio de Janeiro: Pão e Rosas: 191-211.

CHESNAIS, François (1996), A Mundialização do Capital, São Paulo: Xamã, 1996.

GONÇALVES, Reinaldo (2008), "Blindagem do Brasil à crise externa é de «papel crepom»", in Correio da Cidadania. Entrevista concedida a Valeria Nader. Disponível em: http://tinyurl.com/ d80o4f3.

GRANEMANN, Sara (2005), Para uma interpretação Marxista da 'Previdência Privada'. Tese de Doutorado - Universidade Federal do Rio de Janeiro, Programa de Pós-Graduação em Serviço Social.

HARVEY, David (2005), O novo imperialismo, São Paulo: Loyola.

MARINI, Ruy Mauro (2005), "Dialética da dependência”, in R. Traspadini e J. P. Stedile, J. P. (org.). Ruy Mauro Marini: vida e obra, São Paulo: Expressão Popular: 181-194.

MARX, Karl e ENGELS, Friedrich (1998), Manifesto do partido comunista (Prólogo de José Paulo Netto), São Paulo: Cortez.

MOTA, Ana Elizabete (1995), Cultura da Crise e Seguridade Social. Um estudo sobre as tendências da previdência e da assistência social brasileira nos anos 80 e 90, São Paulo: Cortez.

MOTA, Ana Elizabete (2006), “Seguridade Social Brasileira: Desenvolvimento Histórico e Tendências Recentes”, In Serviço Social e Saúde, São Paulo: Cortez.

MOTA, Ana Elizabete; AMARAL, Angela e PERUZZO, Juliana (2012), "O novo desenvolvimentismo e as políticas sociais na América latina”, In Mota, A. E. (org.) Desenvolvimentismo e Construção de Hegemonia, São Paulo: Cortez.

MOTA, Ana Elizabete (2013), A precarização do trabalho na indústria do vestuário: apontamentos sobre a realidade brasileira e a portuguesa, SOCIUS Working Papers n.․ 4. Disponível em: http:// pascal.iseg.utl.pt/socius/publicacoes/wp/wp_04_2013.pdf). 
POLANYI, Karl (2000), A Grande Transformação: as origens da nossa época, Rio de Janeiro: Campus.

SEN, Amartya (2000), Desenvolvimento como liberdade, São Paulo: Companhia das Letras.

SICSÚ, João; PAULA, Luís Fernando e MICHEL, Renaut (org.) (2005), Novo-desenvolvimentismo: um projeto nacional de crescimento com equidade social, Rio de Janeiro: Fundação Konrad Adenauer.

BRASIL, Relatório de atividades (2011), Brasilia: PREVIC, 2011. [Online], disponível em: http:// www.mpas.gov.br/arquivos/offi ce/1_121005-161831-326.pdf [Consultado em outubro 2012].

BRASIL. Ministério da Saúde (2011), Agência Nacional de Saúde Suplementar. Brasília, [Online], disponível em: http://bvsms.saude.gov.br/bvs/periodicos/

caderno_informacao_suplementar_set2011.pdf [Consultado em novembro de 2012].

CEPAL - Comissão Econômica Para a América Latina e o Caribe (2010), Relatório do Programa de Assentamentos Humanos da Organização das Nações Unidas (ONU-Habitat). [Online], disponível em: $<$ http://www.cepal.org/>. [Consultado em novembro de 2012].

CEPAL (2011), Programas de Transferencias condicionadas: Balance de la experiencia reciente en América Latina y el Caribe. CEPAL/ ASDI (Agencia Sueca de Cooperación Internacional para el Desarrollo). Santiago de Chile. [Online], disponível em: http://tinyurl.com/cwy $57 \mathrm{~cm}$ [Consultado em novembro de 2012].

CEPAL (2009), Relatório preliminar das economias da América Latina e Caribe. Disponível em: <http:// www.cepal.org/>. [Consultado em novembro de 2012].

IBGE Pesquisa Nacional por Amostra de Domicílio (2012), [Online], Disponível em: http:// www.ibge.gov.br. [Consultado em: novembro de 2012].

\section{NOTAS}

1. Importa destacar que os países latinoamericanos não vivenciaram a experiência do Estado Social. No caso brasileiro, é apenas em 1988 que se instituem as bases formais e legais do que poderia ser um Estado de Bem-Estar (Mota, 1995). Contudo, nos anos iniciais da década de 90, em face dos imperativos neoliberais, assistiu-se ao desmonte precoce das políticas públicas e a uma profunda regressão no exercício dos direitos e na universalização da seguridade social brasileira (Mota, 2006).

2. A crise orgânica é concebida por Gramsci como aquela que, ao se originar no ambiente econômico, transita para o ambiente político. Portanto, afeta tanto os padrões de acumulação de capital, como das estratégias de dominação ideopolíticas.

3. Emprego a noção segundo a inspiração gramsciana - como, aliás, está subjacente em anteriores trabalhos (cf. Mota, 1995).

4. James Wolfensohn assume a presidência do Banco em junho de 1995 e reafirma o compromisso da instituição em relação às metas de crescimento econômico e combate à pobreza.

5. O diagnóstico cepalino indicava, para os países subdesenvolvidos, a adoção de políticas de diversificação econômica, basicamente via industrialização, como meio para que o mercado interno passasse a ser o motor da acumulação e do crescimento, em lugar da demanda externa de produtos primários. No entanto, não bastava somente a ação do mercado; seria importante a intervenção do Estado, no planejamento, na indução, no fi nanciamento e como investidor direto, para que o processo de industrialização se efetivasse (Mota, Amaral e Peruzzo, 2010). 


\section{RESUMOS}

Este artigo aborda as tendências das políticas sociais no Brasil e demais países latino-americanos nos anos 2000. Discorre sobre os fundamentos da crise capitalista deste século e sobre o paradigma do novo-desenvolvimentismo adotado pelos governos de centro-esquerda da região. Destaca a relação entre financeirização, crescimento econômico e políticas sociais compensatórias. Expõe as tendências das políticas sociais públicas e evidencia o paradoxo entre a expansão das políticas de combate à pobreza extrema e a mercantilização dos serviços sociais. Conclui pela existência de compatibilidade entre a expansão dos programas de transferência de renda e o pensamento social-liberalista e afirma que aqueles têm incidência na redução da pobreza, mas não na desigualdade social entre ricos e pobres.

This article is about the tendencies of the social policies in Brazil and other Latin American countries in the 2000 years. It talks about the basis of the capitalist crisis of this century and the paradigm of the new development adopted by the centre-left wing governments of the region. The article also calls attention to the relationship between economic development, compensatory social policies and financial interests. It emphasises the tendencies of the social policies adopted by the public setor, showing evidences of the paradox between the expansion of the policies against extreme poverty and the mercantile nature of social services in the region. It concludes that the expansion of social programmes of transfer of income is compatible with the social-liberal thinking and its influence on the reduction of poverty, but not on the inequality between rich and poor.

Cet article examine les tendances des politiques sociales au Brésil et autres pays d'Amérique Latine dans les années 2000. On analyse les fondements de la crise capitaliste de ce siècle et le nouveau paradigme du développement adopté par les gouvernements de centre-gauche dans la région. Il met en évidence le rapport entre la financiarisation, la croissance économique et les politiques sociales compensatoires. On expose les tendances dans les politiques sociales publiques, en soulignant le paradoxe entre l'expansion des politiques de lutte contre la pauvreté et la marchandisation des services sociaux. L'article conclut qu'il y a un rapport entre l'expansion des programmes de revenu minimum et la pensée sociale libérale et affirme que ces programmes ont un impact sur la réduction de la pauvreté, mais ils ne son pas capables de réduire les inégalités sociales entre les riches et les pauvres.

\section{ÍNDICE}

Palavras-chave: crise, desenvolvimentismo, políticas sociais, América Latina

Keywords: crisis, development, social policies, Latin America

Mots-clés: crise, développement, politiques sociales, Amérique Latine 
AUTOR

ANA ELIZABETE MOTA

Professora do Departamento de Serviço Social da Universidade Federal de Pernambuco/Brasil bmota@elogica.com.br 